\title{
Forensic Case of Supposedly Poisoned Beer
}

\author{
Wilson I B Onuigbo* \\ Department of Pathology, Medical Foundation \& Clinic, Nigeria
}

*Corresponding author: Wilson I B Onuigbo, Department of Pathology, Medical Foundation \& Clinic, 8 Nsukka Lane, Enugu-410000, Nigeria

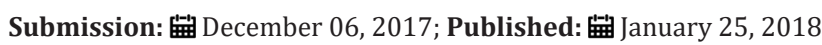

\begin{abstract}
A man drank beer and was so upset as to sue the company for damages on the grounds of laboratory findings. However, the case failed. This was due to the findings which I systematically dismantled in the court.
\end{abstract}

Keywords: Beer; Consumption; Complaint; Laboratory; Falsification; Quashed case

\section{Introduction}

Consider a man who probably enjoyed his beer but then turned round to claim heavy damages from the Guinness (Nigeria) Ltd for his stomach upset. He alleged that he suffered seriously from consuming its beer! As the Company's lawyer turned out to be my acquaintance, he duly turned in the relevant documents with the following promise: "Your fee should be for opinion and possible set of questions for cross examination at this stage."

\section{The Case}

I received the following Annexures and commented thus:

\section{Annexure A}

This is a treatment sheet. It does not help the Court as there is no history. When did this man take the alleged beer? Did he take it alone or with some food? Not only beer but also other edibles can give rise to gastroenteritis. Notice that the sheet contains two diagnoses, namely, bronchitis and gastroenteritis, i.e., infection of the air passages and food passages. Note also, the last prescription on that page. It is for "Neo-Cortef Eye Drop." Clearly, this man had disease of the lungs, intestines and eyes. Are these diseases, of their own, being suffered by a debilitated man? Certainly, the intestines cannot be singled out for accusation in respect of one of his different illnesses during 3 days.

\section{Annexure B}

This appears to be from Park Lane Hospital unlike the first one from the Polyclinic. This Annexure shows that it was on the fourth day of treatment (and not necessarily of the illness) that laboratory investigations started. Why the delay? Moreover, this page contains a prescription for Emetine injection. Now, this is a specific treatment for amebic dysentery. Therefore, it was not for gastroenteritis per se, indicating uncertainty in the mind of the doctor.

\section{Annexure C}

There is no date on this form. It is useless to the Court. When was the test ordered? When was it carried out? When was it reported on?

\section{Annexure D}

This reworded test is the same as an earlier one. Why the duplication? Can it be that a different result was being expected? Why resort to a private laboratory in preference to the Teaching Hospital?

\section{Annexure E}

This brings out in many ways the inadequacies of the private laboratory:

a. Although culture requires time for the germs to grow and be identified, yet the report came out on the same day as the request. Why the undue haste? Was it to incriminate the beer?

b. The report contained the three words "BACCILI," "YEALDED" and SPICIES." Each of them is wrongly spelt. The correct spellings are bacilli, yielded and species. Do these errors not point to the incompetence of the writer, signatory, or both? Should such a laboratory's result be trusted?

c. Even the report itself is valueless. It merely stated that there was a heavy growth of PSEUDOMONAS and COLIFORM species. How many of these species-types are present in our surroundings? Can the purported results of the unclassified species mean anything in the causation of disease? No!

d. Then there is the most ominous fact concerning the day the beer was actually cultured. If the beer was drunk some days earlier, what precautions were taken to ensure that no extraneous germs entered the alleged bottle? Is it not the established practice 
to heat the wire-loop used in culturing suspected material in order to kill extraneous germs before using it? Does this not show that laboratory workers take every precaution to avoid introducing extraneous germs into whatever is being cultured? If germs are ubiquitous and this precaution is deemed necessary whenever cultures are being made, what precaution was taken in the patient's own home to prevent contamination by germs? In other words, as contamination cannot be ruled out here, the case must fail.

\section{Discussion}

Subsequently, I had to attend in person for cross examination at the High Court. Among the points brought to light, there was the issue of the role of toxins in gastroenteritis. I explained that germs manifest an incubation period in the human body. This is the time taken for them to grow and then to produce the toxins inimical to the body. Therefore, immediate or early vomiting and diarrhea after taking beer must be due to the preformed toxins present in it. In that case, the beer bottle itself should have been submitted to a Forensic Laboratory for investigation and not to a Bacteriology Laboratory for culture. In effect, even a good result from such culture must necessarily be of no value to the court.

\section{Conclusion}

As Barrister Mojekwu eventually communicated, "I write this letter to thank you for the wonderful evidence you gave in the court whereby you cleared a lot of misconception about Exhibit " $\mathrm{C}$ " the lab report from WABSCO and Exhibit "A" the treatment card. Your expert opinion was fully accepted by the Court during the address stage." 